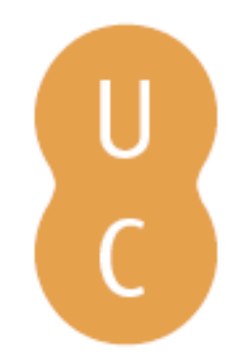

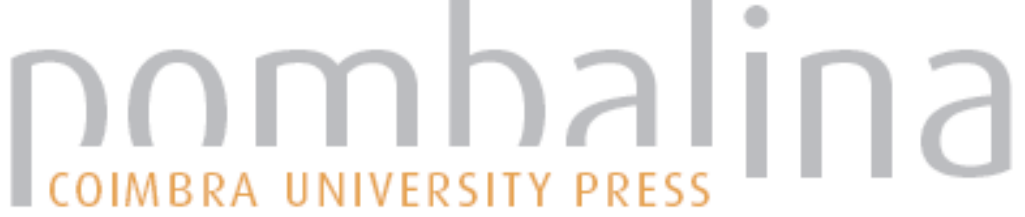

\section{Simulação de cheia seguida de inundação na cidade de Mirandela}

Autor(es): $\quad$ Gouveia, Maria; Lourenço, Luciano; Ferreira, Carmen; Costa, Francisco

Publicado por: Imprensa da Universidade de Coimbra; RISCOS - Associação

URL

persistente: URI:http://hdl.handle.net/10316.2/34817

DOI: $\quad$ DOI:http://dx.doi.org/10.14195/978-989-96253-3-4_26

Accessed : $\quad$ 26-Apr-2023 11:07:14

A navegação consulta e descarregamento dos títulos inseridos nas Bibliotecas Digitais UC Digitalis, UC Pombalina e UC Impactum, pressupõem a aceitação plena e sem reservas dos Termos e Condições de Uso destas Bibliotecas Digitais, disponíveis em https://digitalis.uc.pt/pt-pt/termos.

Conforme exposto nos referidos Termos e Condições de Uso, o descarregamento de títulos de acesso restrito requer uma licença válida de autorização devendo o utilizador aceder ao(s) documento(s) a partir de um endereço de IP da instituição detentora da supramencionada licença.

Ao utilizador é apenas permitido o descarregamento para uso pessoal, pelo que o emprego do(s) título(s) descarregado(s) para outro fim, designadamente comercial, carece de autorização do respetivo autor ou editor da obra.

Na medida em que todas as obras da UC Digitalis se encontram protegidas pelo Código do Direito de Autor e Direitos Conexos e demais legislação aplicável, toda a cópia, parcial ou total, deste documento, nos casos em que é legalmente admitida, deverá conter ou fazer-se acompanhar por este aviso. 

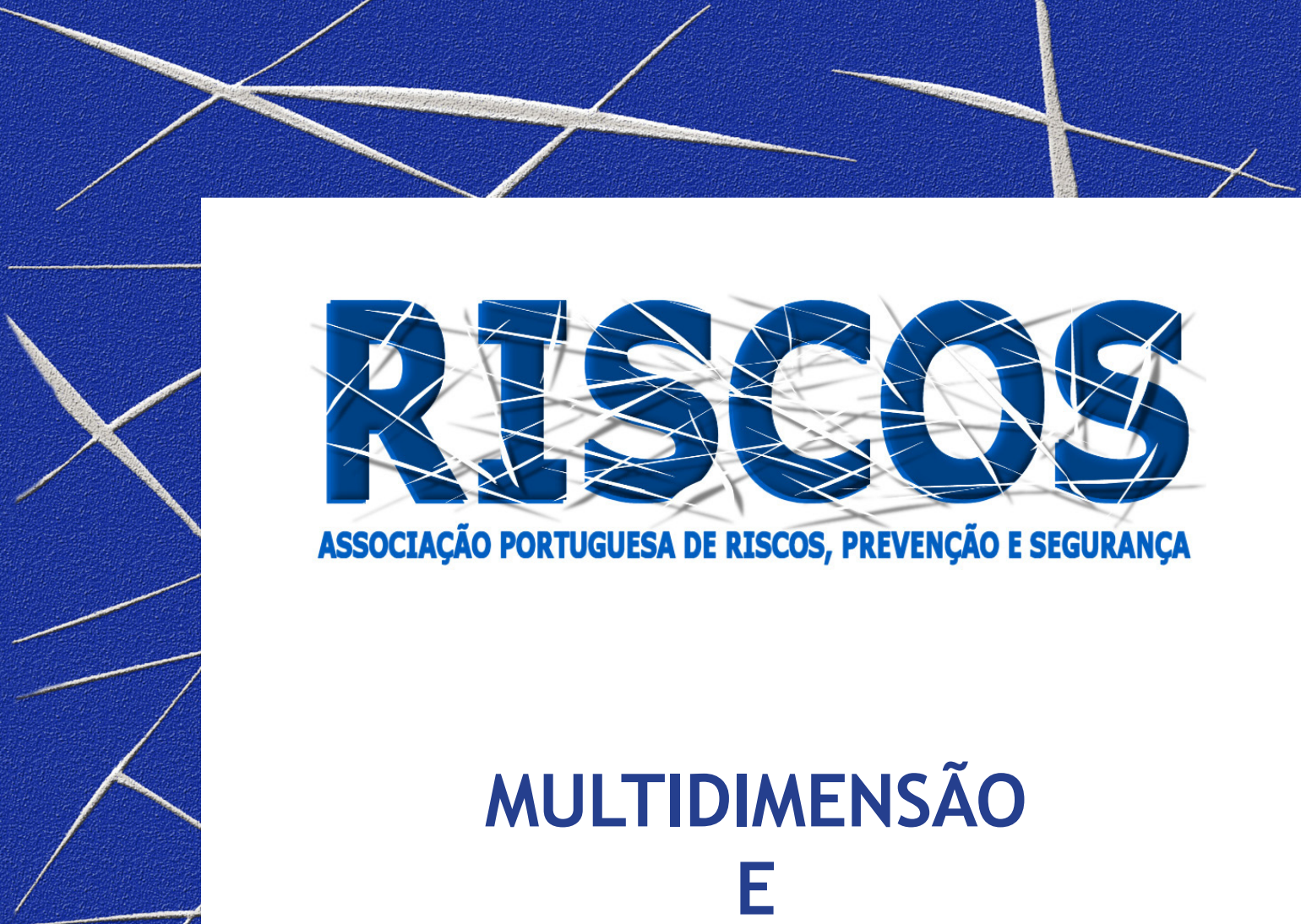

ASSOCIAÇÃO PORTUGUESA DE RISCOS, PREVENCCÃO E SEGURANÇA

MULTIDIMENSÃO

E
TERRITÓRIOS DE RISCO

III Congresso Internacional

I Simpósio Ibero-Americano

VIII Encontro Nacional de Riscos

Guimarães

2014 


\title{
SIMULAÇÃO DE CHEIA SEGUIDA DE INUNDAÇÃO NA CIDADE DE MIRANDELA
}

\author{
Maria Gouveia \\ Doutoranda, Departamento de Geografia e CEGOT, \\ Faculdade de Letras da Universidade de Coimbra \\ mmalgouveia@gmail.com \\ Luciano Lourenço \\ Departamento de Geografia e CEGOT, \\ Faculdade de Letras da Universidade de Coimbra \\ luciano@uc.pt \\ Carmen Ferreira \\ Departamento de Geografia e CEGOT, \\ Faculdade de Letras da Universidade do Porto \\ dra.carmenferreira@gmail.com \\ Francisco Costa \\ Departamento de Geografia e CEGOT, \\ Instituto de Ciências Sociais da Universidade do Minho \\ costafs@geografia.uminho.pt
}

\begin{abstract}
RESUMO
A ocorrência de cheias no rio Tua e as consequentes inundações na cidade de Mirandela, são conhecidas pelo menos desde o século XV. Mais recentemente, também se verificaram nos anos de 1959, 1960, 1966, 2001, 2009 e 2012. Sabendo-se que a ocorrência de inundações na cidade de Mirandela é um fator condicionante para a vida dos cidadãos que aí residem, trabalham ou se deslocam para a visitar, pensou-se ser importante simular uma cheia, seguida de inundação. Utilizando-se ferramentas de Sistemas de Informação Geográfica, foi possível elaborar uma animação em 3D, que permitiu a visualização sequencial da simulação de uma cheia e consequente inundação ao longo das margens do rio Tua. De seguida, efetuou-se a avaliação das consequências e uma proposta de medidas mitigadoras.

Deste modo, pretende contribuir-se para um melhor conhecimento do risco de inundação na cidade de Mirandela, podendo proteger-se mais eficazmente pessoas, animais e bens patrimoniais.
\end{abstract}

Palavras-chave: Mirandela, cheia, inundação, simulação.

\section{Introdução}

Sabendo-se que a ocorrência de inundações na cidade de Mirandela é um fator condicionante para a vida dos cidadãos que aí residem, trabalham ou se deslocam para a visitar, pensou-se ser importante simular uma cheia, seguida de inundação.

A simulação da ocorrência de uma cheia no rio Tua, seguida de inundação ao longo das suas margens, em plena cidade de Mirandela, permite conhecer os efeitos e os prejuízos que esta poderá causar direta ou indiretamente aos comerciantes, residentes ou outras entidades.

Desde o século XV que são conhecidas as inundações na cidade de Mirandela, altura dos primeiros relatos sobre a manifestação deste fenómeno podendo, mais recentemente, alguns deles ser lidos em jornais locais e regionais (Notícias de Mirandela, Mensageiro de Bragança, Jornal do Nordeste e Jornal Terra Quente), publicados nos anos de 1959, 1960, 1966, 2001, 2009 e 2012.

\section{Simulação e animação de cheia seguida de inundação}

"Simulação é a imitação de operações de processos reais ou sistemas sobre o tempo. Simular envolve a geração de uma história artificial do sistema e a partir da observação desse histórico 
é possível inferir características do sistema real em representação.” (Leonel Deusdado, 2008:25).

Tendo-se tomado conhecimento das áreas inundadas na cidade de Mirandela, ao longo dos anos de 1959, 1960, 1966, 2001, 2009 e 2012 (Maria Gouveia e Luciano Lourenço, 2013), irá efetuarse uma simulação e uma animação tridimensional de cheia e consequente inundação entre a foz da ribeira de Carvalhais e a ponte Europa, afetando cinco locais (figs. 1 e 2).

"Animar, significa literalmente, dar vida a algo, mover algo que não pode mover-se por si só." (Leonel Deusdado, 2008:23). A animação permite a visualização de uma simulação ao longo de uma sequência temporal.

As animações tridimensionais foram elaboradas através da utilização da extensão $3 D$ Analyst do software de Sistemas de Informação Geográfica ArcGIS, versão 10.2, (licença que a Universidade de Coimbra disponibiliza aos seus alunos). 0 ambiente de visualização disponível através da extensão 3D Analyst, que foi utilizado, denomina-se ArcScene.

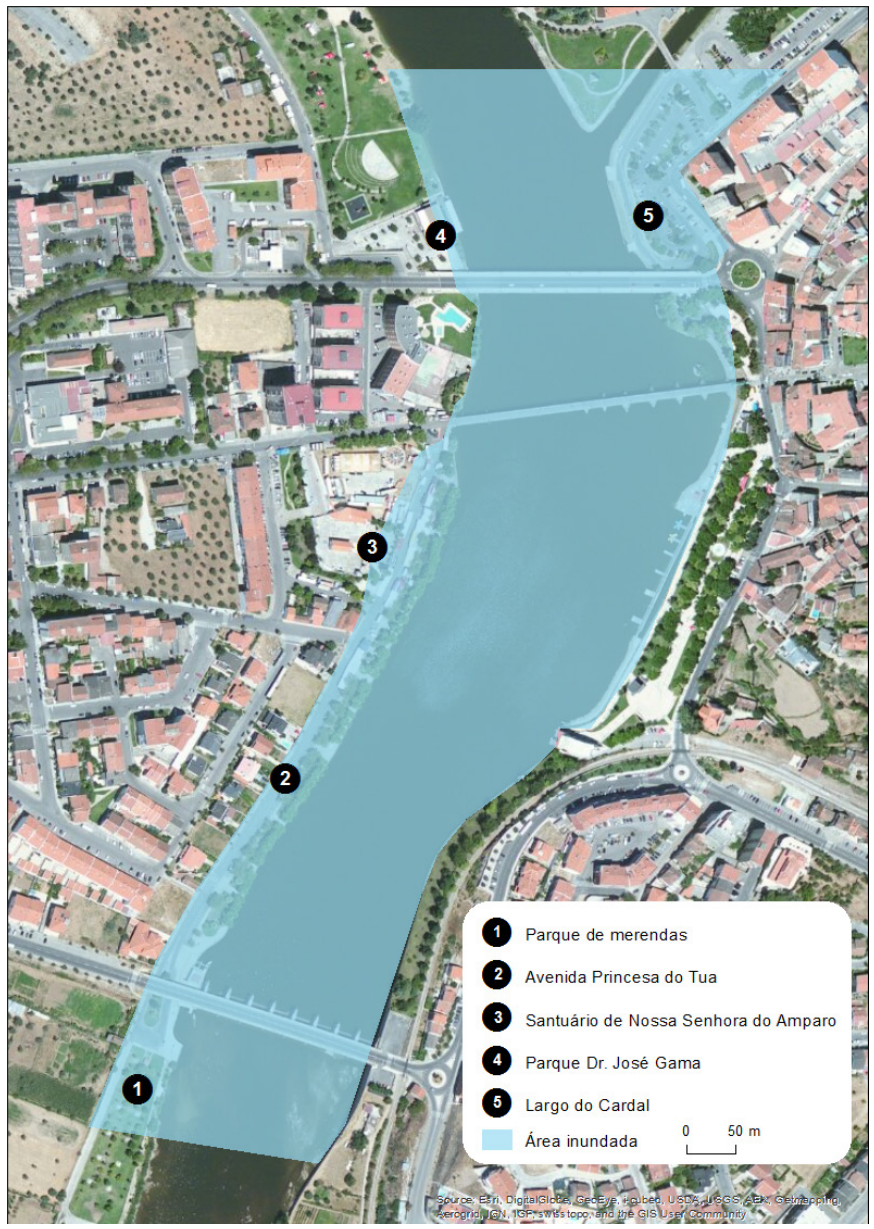

Figura 1 - Áreas inundadas na cidade de Mirandela pela simulação de uma cheia.

Fonte: World Map Imagery, ESRI, 2014. 


\section{Efeitos das inundações e medidas mitigadoras}

Através da leitura de jornais locais e regionais, designadamente, Notícias de Mirandela, Mensageiro de Bragança, Jornal do Nordeste e Jornal Terra Quente, ficaram a conhecer-se as consequências das inundações verificadas nos anos de 1959, 1960, 1966, 2001, 2009 e 2012, nomeadamente: estragos na ponte e corte ao trânsito; habitações, viaturas e estabelecimentos comerciais e industriais inundados; destruição de campos agrícolas, vias de comunicação, vedações e muros; pessoas isoladas e morte de animais; árvores derrubadas e lodo nos jardins.
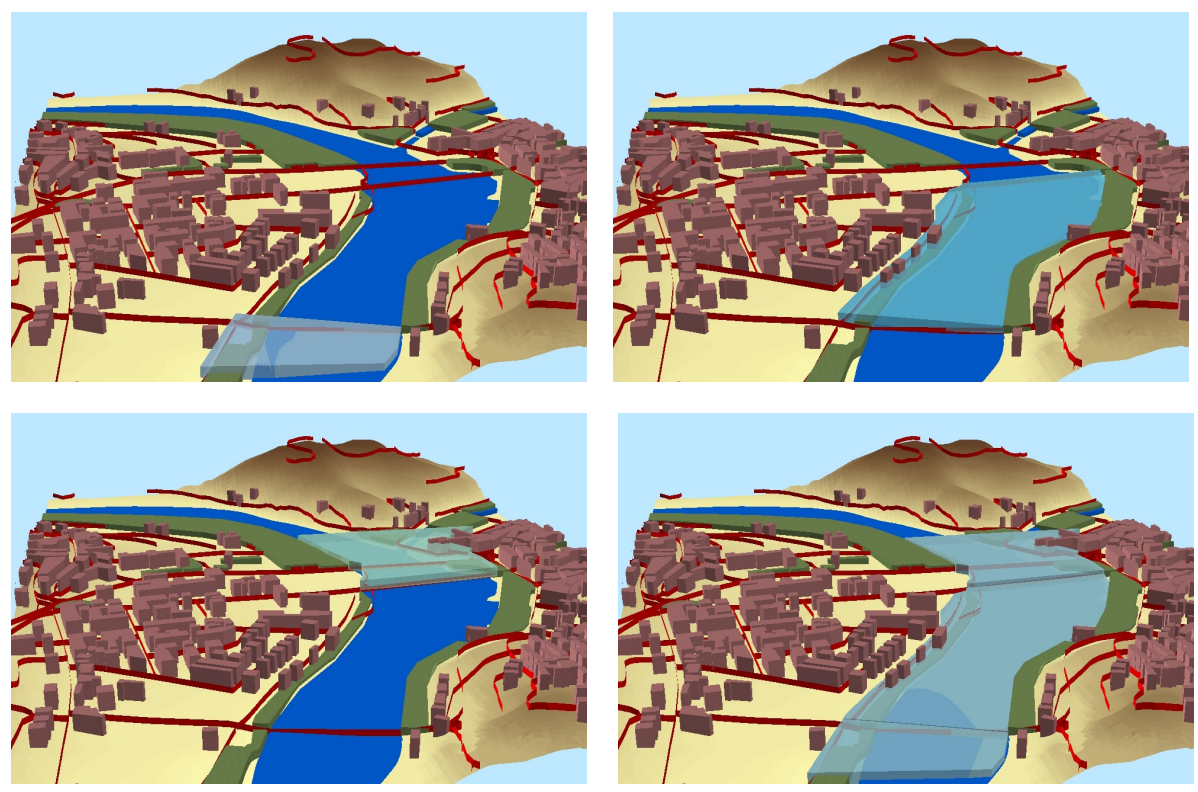

Figura 2 - Simulação e animação 3D de cheia e consequente inundação na cidade de Mirandela - Sequência temporal.

Fonte: Carta Militar de Portugal, 1/25000, folhas 76 e 77, IGeoE, 1995.

Conhecendo-se os diversos relatos, foi possível aferir os efeitos da inundação simulada e representada na figura 1 , nomeadamente:

- O parque de merendas ficou degradado e está impossibilitado de ser utilizado;

- Grande parte da Avenida da Princesa do Tua foi inundada, o trânsito foi interdito e foram afetadas oito casas de habitação e um estabelecimento de restauração e bebidas;

- O jardim no patamar inferior do Santuário de Nossa Senhora do Amparo ficou degradado e duas estátuas foram danificadas;

- Parte do Parque Dr. José Gama, foi inundado, salientando-se os estragos na esplanada de um estabelecimento de restauração e bebidas;

- No estacionamento no Largo do Cardal, foram inundadas três viaturas aí estacionadas e este local foi encerrado para efeitos de estacionamento.

A partir da simulação que se efetuou, foi possível determinar, aproximadamente, os prejuízos (em euros) associados aos efeitos acima mencionados (tabela I). 
Tabela I - Simulação de cheia e consequente inundação na cidade de Mirandela - Prejuízos (valores calculados com base em pesquisas em sítios da internet)

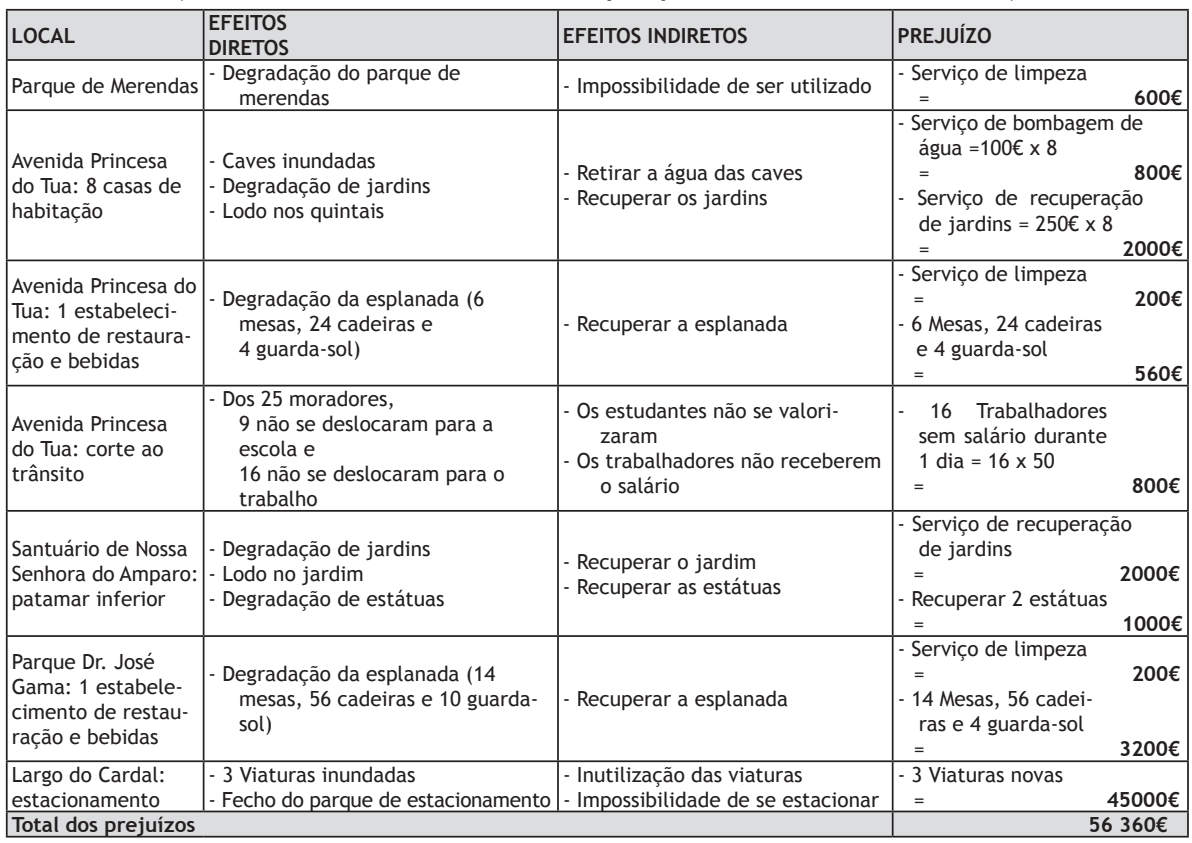

O valor total dos prejuízos relacionados com os efeitos diretos e indiretos derivados da simulação de cheia seguida de inundação ascende aos 56.360,00€, sendo este um valor considerável que deve ser tido em devida conta. De facto, os efeitos e os prejuízos das inundações que ocorreram até à atualidade, ultrapassam em muito o valor calculado, logo, seria muito mais vantajoso que se procedesse à implementação de algumas medidas de redução da exposição às vulnerabilidades (estruturais e não estruturais). Assim, para minimizar os prejuízos nos cinco locais afetados, propõem-se as seguintes medidas concretas:

- Parque de merendas, Avenida Princesa do Tua e Jardim, no patamar inferior do Santuário de Nossa Senhora do Amparo - construção de uma proteção/dique ao longo do rio Tua, a jusante do parque de merendas;

- Parte do Parque Dr. José Gama - sistema de aviso da ocorrência de cheias de modo a que se possam salvaguardar todos os bens, efetuar um seguro contra as inundações e promover ações anuais de informação sobre cheias e inundações;

- Largo do Cardal - instalar um sistema aviso da ocorrência de cheias, de modo a nesses dias evitar o estacionamento e a retirar atempadamente todas as viaturas estacionadas, bem como a colocação de uma placa com o aviso de possibilidade de ocorrência de cheias.

\section{Conclusão}

O exercício de criação de uma simulação e animação tridimensional, elaboradas em ambiente de Sistemas de Informação Geográfica, foi bastante proveitoso para se conhecerem e visualizarem, em três dimensões, as áreas que ficaram inundadas. Com base na identificação dessas áreas e nas caraterísticas do espaço urbano, foi possível propor-se um conjunto de 
medidas de redução da exposição às vulnerabilidades, específicas para cada um dos cinco locais inundados.

Perspetivando-se um futuro que se pretende ser mais seguro para quem habita ou visita a cidade de Mirandela, efetuar-se-ão mais estudos sobre possíveis soluções para se minimizarem os impactes provocados pelas cheias.

\section{Bibliografia}

Deusdado, Leonel (2008) - Ambientes virtuais povoados com simulação eficiente de detecção de colisões e planeamento de trajectos em navegação realmente 3D. Dissertação de Doutoramento. Braga, Universidade do Minho, $236 \mathrm{p}$.

Maria Gouveia e Luciano Lourenço (2013) - "Simulação de um incêndio florestal, a que se seguiu precipitação intensa, com consequente inundação". Grandes Incêndios Florestais, Erosão, Degradação e Medidas de Recuperação dos Solos, Universidade do Minho, Guimarães, p. 111-120, ISBN: 978-989-968107214-2-5. 